\title{
ANTLEY-BIXLER SYNDROME IN A SISTER AND BROTHER
}

\author{
Koichi Suzuki, ${ }^{1}$ Yasusi Kanda, ${ }^{1}$ Kohachiro Sugiyama, ${ }^{1}$ \\ Toshiyuki KatoH, ${ }^{1}$ Yoshiro WADA, ${ }^{1}$ and Yoji Yasui ${ }^{2}$ \\ ${ }^{1}$ Department of Pediatrics, Nagoya City University Medical School, \\ Mizuho-ku, Nagoya 467, Japan \\ ${ }^{2}$ Department of Pediatrics, Nagoya City Josai General Hospital, \\ Nakamura-ku, Nagoya 453, Japan
}

\begin{abstract}
Summary A sister and brother both with the clinical and radiographic features of Antley-Bixler syndrome are reported. Their parents were first cousins. Analysis of these siblings and seven other patients reported in the literature indicates autosomal recessive inheritance for the syndrome.
\end{abstract}

\section{INTRODUCTION}

Since the first description of the Antley-Bixler syndrome by Antley and Bixler (1975), seven patients with the syndrome have been reported. Its clinical features include craniosynostosis, midface hypoplasia, dysplastic ears, radiohumeral synostosis, contracture of joints, arachnodactyly, femoral bowing and femoral fractures. Of the seven patients so far described, five were sporadic while the other two (Schinzel et al., 1983) were sisters. No consanguinity was noted in any of the parents. We report here a sister and brother, both with the typical clinical features of AntleyBixler syndrome, born to parents who were first cousins.

\section{CASE REPORTS}

\section{Patient 1}

Y.K, a girl was born after 40 weeks' pregnancy to a 23 -year-old primigravida mother and 27-year-old father. The parents were first cousins. Her birth weight was $1,945 \mathrm{~g}(-3.3 \mathrm{SD})$, length $44.5 \mathrm{~cm}(-2.9 \mathrm{SD})$, and head circumference $29.5 \mathrm{~cm}$ $(-2.9 \mathrm{SD})$. The mother had a high fever at the 10th week of pregnancy for which she took aspirin. Otherwise, the pregnancy, labor and delivery were unremarkable. The family history was negative for congenital anomaly. When first examined by us at the age of 2 days, she had multiple malformations including brachycephaly,

Received March 11, 1986; revised version received May 20, 1987; Accepted July 9, 1987 
frontal bossing, a large anterior fontanel, sparse hair, midface hypoplasia, a depressed nasal bridge with a bulging tip, choanal stenosis, a long philtrum, a small mouth, a high and narrow palate with a posterior cleft, and dysplastic and low set ears with stenotic external auditory canals. Anomalies of her limbs included contractures of the elbows, wrists, knees and fingers, arachnodactyly, syndactyly, hypoplastic and

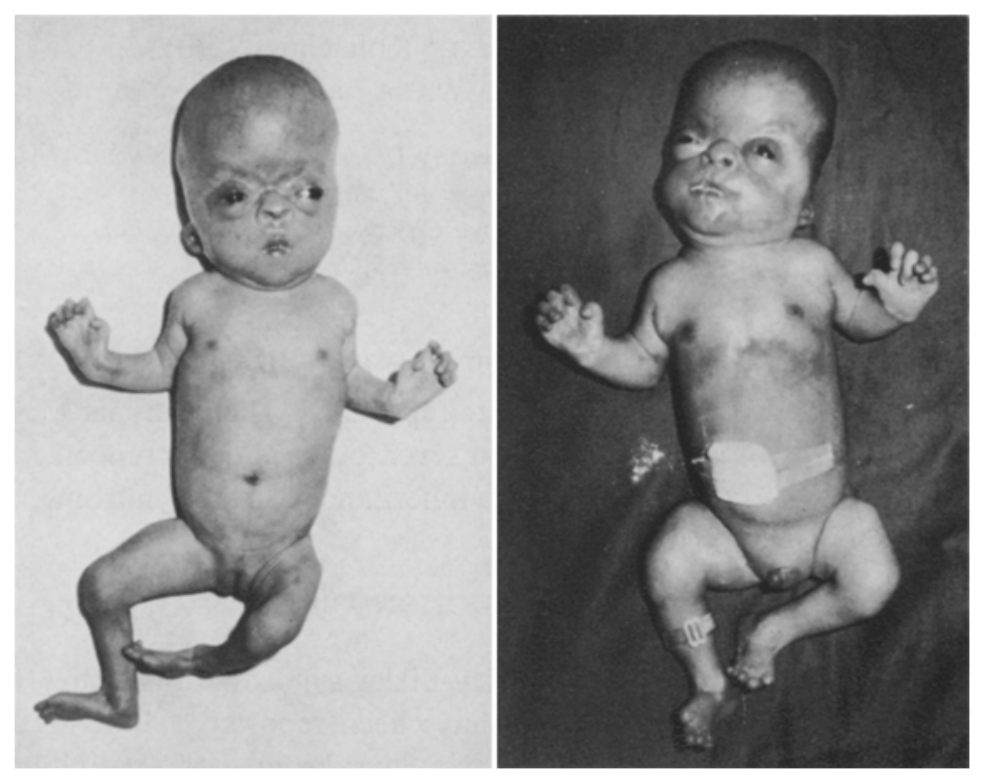

Fig. 1. Photographs of the siblings. Left, patient 1 on the 10th day of life; right, patient 2 on the 3 rd of life.
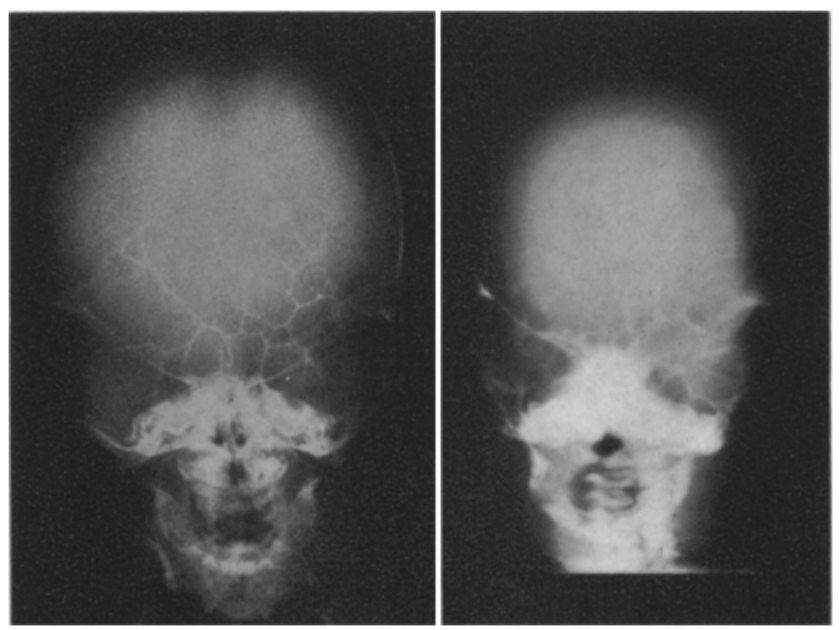

Fig. 2. Roentgenograms of the skull. Left, patient 1; right, patient 2. 

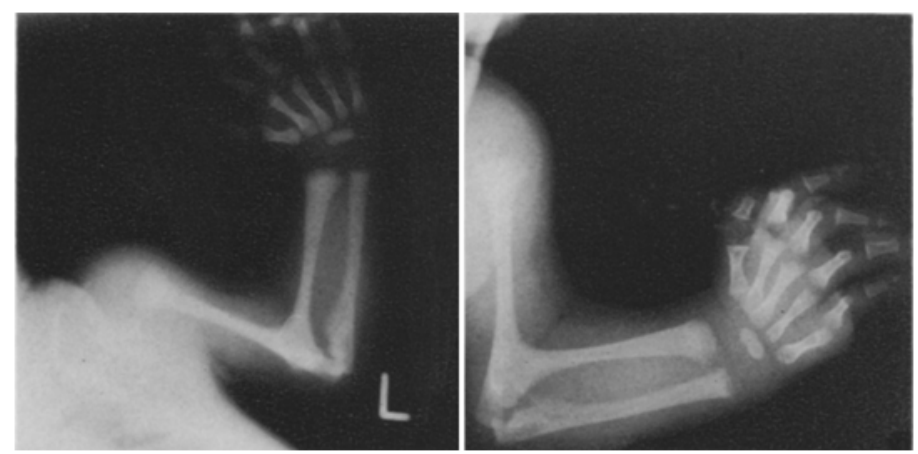

Fig. 3. Radiohumeral synostosis. Left, patient 1; right, patient 2.
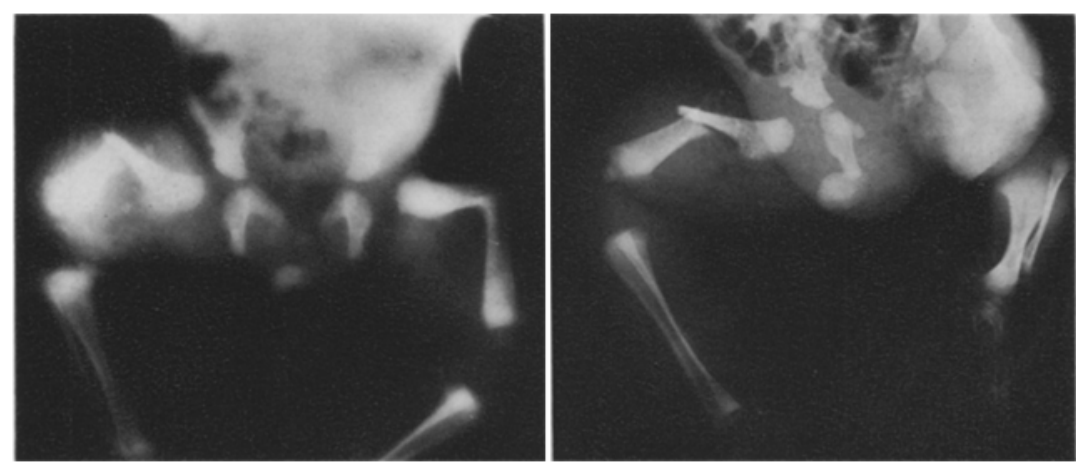

Fig. 4. Bowing of the femurs, which are hypoplastic, with fracture. Left, patient 1, right, patient 2.

aplastic fingers and toes, hypoplastic dermal patterns, and hypoplastic labia majora (Fig. 1, left).

Radiographic examinations revealed craniosynostosis, a cystic bone defect of the occipital cranium, bilateral femoral bowing and fracture of the right femoral bone, a narrow chest and pelvis (Fig. 2, 3, 4, left; Table 1). CT-scan revealed communicating hydrocephalus.

Her chromosomal analysis revealed 46,XX with G-banding. Her ECG, urinary amino acid excretion and TORCH screening were all normal. She was gavage fed due to feeding difficulty.

She died of aspiration pneumonia at the age of 7 months. Autopsy was not granted.

\section{Patient 2}

T.K, a younger brother of patient 1, was born by spontaneous vertex delivery after a 39 weeks' pregnancy two years after the birth of patient 1 . He weighed $2,572 \mathrm{~g}(-1.7 \mathrm{SD})$ and measured $45.4 \mathrm{~cm}(-2.4 \mathrm{SD})$. He had a head circumference 
K. SUZUKI et al.

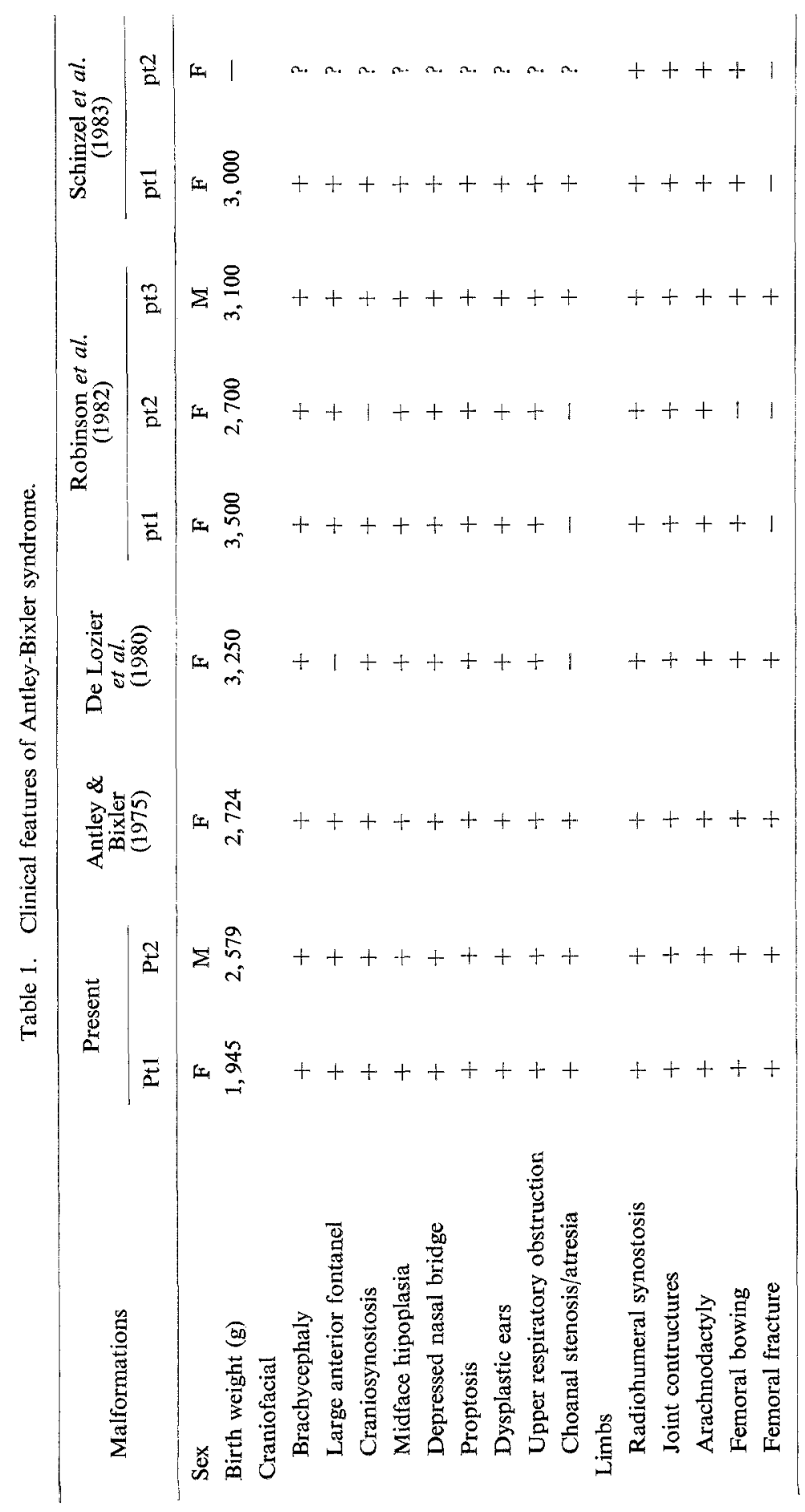


of $30.0 \mathrm{~cm}(-2.6 \mathrm{SD})$. When first seen by us at the age 2 days, he had multiple malformations almost identical with those of his elder sister (Fig. 1, 2, 3, 4, right; Table 1). He had a small penis and undescending testes.

Routine laboratory studies, immunological examinations, urinary amino acid analysis, TORCH screening and ECG were normal, except for elevated serum alkaline phosphatase activity $(826 \mathrm{mU} / \mathrm{ml}$ on 19 days, $588 \mathrm{mU} / \mathrm{ml}$ on 31 days and 590 $\mathrm{mU} / \mathrm{ml}$ on 38 days). Parathormone $(0.1 \mathrm{ng} / \mathrm{ml})$ and $25-\mathrm{OH}$-vitamin $\mathrm{D}(5 \mathrm{ng} / \mathrm{ml})$ were low. Calcitonin was high at $271 \mathrm{pg} / \mathrm{ml}$. His chromosomes were $46, X Y$. A CT-scan and ultrasound scans revealed communicating hydrocephalus.

In two months, he suffered from pulmonary hemorrhage following upper respiratory infection and died. Autopsy revealed no visceral malformations other than those mentioned above, and the structure of bones and cartilages were pathologically normal.

\section{DISCUSSION}

Both the sister and brother we described had the constellation of multiple malformations found in the Antley-Bixler syndrome. They included craniosynostosis, radiohumeral synostosis, and femoral bowing.

Additional defects noted in the siblings included midface hypoplasia with characteristic facial appearance and ears, neonatal femoral fractures, and multiple minor anomalies of the limbs. The unique combination of clinical and radiographic abnormalities observed in both the sister and brother allowed ready diagnosis.

The occurrence of Antley-Bixler syndrome in siblings of both sexes born to consanguineous parents suggests its genetic origin. Seven patients with the syndrome have been described (Antley and Bixler, 1975; De Lozier et al., 1980; Robinson et al., 1982; Schinzel et al., 1983). Of these, five were sporadic, while the two patients reported by Schinzel et al. (1983) were siblings. The first infant, a girl, died from respiratory failure on 14 days of life. The second child, a female fetus, was therapeutically aborted in 21 weeks of pregnancy in view of ultrasound findings suggestive of the syndrome. Their parents were not related. Including the sister and brother we described, there were two pairs of siblings among the nine reported patients with the syndrome. One pair, the sister and brother we described, were born of the parents who were first cousins. These facts indicate that the syndrome is inherited, most likely in an autosomal recessive fashion. In addition, Lacheretz et al. (1978) described a 10-year-old boy with probably the same disease, born of the parents who were related. Although the boy is not included among the patients with the syndrome in view of skippy documentation, this would further support our interpretation that Antley-Bixler syndrome is an autosomal recessive disorder. 


\section{REFERENCES}

Antley, R. and Bixler, D. 1975. Trapezoidocephaly, midfacial hypoplasia and cartilage abnormalities with multiple synostosis and skeletal fractures. Birth Defects: Original Article Series XI(2): 397-401.

De Lozier, C.D., Antley, R.M., Williams, R., Green, N., Heller, R.M., Bixler, D., and Engel, E. 1980. The syndrome of multisynostotic osteodysgenesis with long bone fractures. Am. J. Med. Genet. $7: 391-403$.

Lacheretz, M., Walbaum, R., and Tourgis, C. 1978. L'acrocephalosynankie. A proposd'une observation avec synostoses multiples. Pediatrie 39: 169-177.

Robinson, L.K., Powers, N.G., Dunklee, P., Sherman, J.S., and Jones, K.L. 1982. The AntleyBixler syndrome. J. Pediatr. 101: 201-205.

Schinzel, A., Savoldelli, G., Briner, J., Sigg, P., and Massini, C. 1983. Antley-Bixler syndrome in sisters. A term newborn and a prenatal diagnosed fetus. Am. J. Med. Genet. 14: 139-147. 